\title{
MODELING AND SIMULATION OF WELDING TEMPERATURE FIELDS IN Cr-Mo STEEL BAR
}

\author{
Reuben Adebare ADEWUYI ${ }^{1 *}$, Jacob Olayiwola AWEDA ${ }^{2}$ \\ ${ }^{1}$ Department of Mechanical Engineering, The Federal Polytechnic, Ado-Ekiti, Nigeria \\ ${ }^{2}$ Department of Mechanical Engineering, University of Ilorin, Ilorin, Nigeria
}

\begin{abstract}
Simulation of welding temperature fields during TIG arc the welding process of $\mathrm{Cr}$-Mo steel bar (ASTM A304) was studied. The results of Simulation models of welding processes help to predict welding parameters effects on the temperature field during and after welding and by this, the failure rate could be estimated and minimized. This paper presents the welding profile model, assembled from $100 \mathrm{~mm}$ by $50 \mathrm{~mm}$ by $20 \mathrm{~mm}$ thick, a Double-Sided Half V-Groove Weld Joint, moving heat source was employed to methodically examine welding temperature fields and transformation in the single-pass butt-welded joint. Unfortunately, the precision of the model rests on many parameters, which cannot be precisely dictated. To resolve this proposition, a calibration process was made by using a Datalogger type $K$ thermocouple 3 channel-LU-MTM-380SD during the welding process on Cr-Mo steel bar. The obtained Experimental results were used as input to run the simulation. Depending on weld joint profile, temperature fields were discovered to vary with distance from the weld centerline which altered the yield stress of weld metal. To realize this goal, a pattern of the 3D model of heat transfer with a moving heat source during welding was simulated in Autodesk Inventor Simulation CFD 2018 Application Software. The results shown that the welding temperature fields have a higher value at the welding center line and decreased towards the edges of the bar. An indication that simulation is a veritable tool to access likely consequence of the welding process at both welded and non-welded portions of steel bar before real machine structural development.
\end{abstract}

Keywords: Weld joints, Yield stress, Temperature fields, and Simulation.

\section{Introduction}

Modeling and Simulation of weldment has advanced from the analysis of laboratory processes to engineering prediction applications due to increase in failure rate. This trend is observed and used to solve the increased complex models which gives a better description of the engineering applications [1]. With or without the application of pressure and filler material, welding as material joining process involves melting at high temperature the sample's weld centre line to suitable temperatures (melting and cooling processes) [2]. Applications of Chromium-Molybdenum (Cr-Mo) steels in various capacities such as oil refineries, fertilizer plants, and power plants, at service temperature of up to $600^{\circ} \mathrm{C}$ and pressure of $30 \mathrm{MPa}$ established its value [3]. Remarkable oxidation resistance, resistance to sulfide corrosion and high-temperature strength, are good properties that distinguished $\mathrm{Cr}$ Mo from other low-alloy steels and are derived functions from chromium and molybdenum alloying elements and they improve with the increase of alloying elements [4]. Tungsten inert gas (TIG) welding, used to weld Cr-Mo steels, arc welding process that produces metal joints by melting process, heating with an arc between a non-consumable electrode and the base metal $[4,5]$. 
In other to minimize weld joint heat-affected zone (HAZ) and weld-metal from cracking after welding operation, alloy content of the base metal, weld metal and associated thermal cycle during welding demand appropriate welding procedures [6,7]. Welding current, arc voltage, welding speed, number of passes, Tungsten electrode diameter and joint geometry during welding operation are process parameters which influence the weld quality and weld deposition rate [8]. The quality of Weld is a function of arc energy generated and transferred as heat input to the workpiece $[8,9]$.

The welding current and electrode diameter set as welding parameters determine total heat input $(\mathrm{H})$ transferred to the weldments per unit time, per unit length of the weld $[10,11]$. Failure of welded Cr-Mo steel bar at weld joints while in service is a common phenomenon that has led to several structural failures as a result of difference in material properties especially yield stress between base metal, weldment and heat affected zone is considered in order to minimise structural failure rate [12,13].

The influence of TIG-Arc physical characteristics on the penetration and weld width under welding conditions revealed that the current density in the arc centre is higher compare to distribution of current density base metal. This gave rise to increasing penetration and weld width of the material being welded significantly[14]. Effects of Diffusion and Metal Vapour in an Argon TIG Welding Plasma shows that the effect of metal vapour on the arc plasma is significant in argon TIG welding. Modelling studied done with argon, considered only diffusion, revealed that the workpiece was exposed to metal vapour. Also, only by including the electric field and diffusion due to temperature gradient, an accurate prediction of metal vapour distribution and arc temperature is obtaind [15].

In this work Material Thickness (20mm), Welding Current (170/160A), Welding Pass (1p) and Tungsten Electrode diameter $(\varnothing 2 \mathrm{~mm})$ were kept constants while varying the position and depth of hole drilled and tapped on the sample where $\mathrm{K}$ type thermocouples were planted to measure temperature fields between the base metal and welded bead which changes with time during the welding operation. The values of the parameters are given in Table 1.

\section{Theoretical analysis}

Analysis of heat flow in arc TIG welding of the semi-infinite workpiece with a moving heat source is presented in Fig. 1. Additionally, typical welding simulation often requires an understanding of the weld pool size and shape. An experimental welding with required process parameters is performed to determine the temperature field in weldment and base material HAZ. As such, it becomes of great interest to develop a computer modeling framework, where an Autodesk CFD model can be used to predict the weld pool size and shape, as well as localized weld temperature fields due to thermal cycles within the solidified and rapidly cooling material. Therefore, Stress analysis and thermal analysis reports from Autodesk Inventor and Autodesk CFD software respectively, which predict material deformations, residual stresses, and failure rate is presented in Figs. (5 - 26).

Also, Reaction Force and Moment on Constraints model and Summary of Finite Element Analysis Result on model is presented in Tables (2-8).

Fig. 1 is a schematic drawing that shows the origin of the coordinate system moves with the heat source at a constant speed, $\mathrm{V}$ in the negative $x$-direction. Except for the initial and final transients of welding, heat flow in a workpiece of sufficient length is steady, concerning the moving heat source. Temperature distribution and the pool geometry do change with time during welding. Heat transfer occurs during the welding process due to different temperature distributed in the workpiece by local heating $[17,18]$. The fundamental modes of heat transfer are conduction, convection and radiation. In general, the rate of heat transfer through conduction is in all directions within the workpiece [11]. 


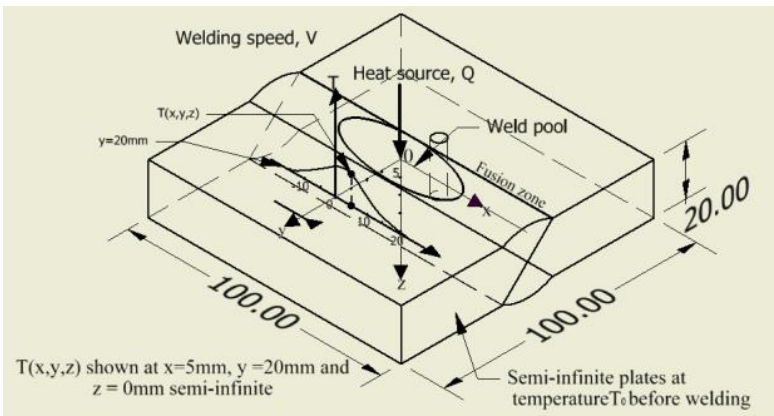

Fig. 1. Two-dimensional heat flow during welding of the semi-infinite workpiece

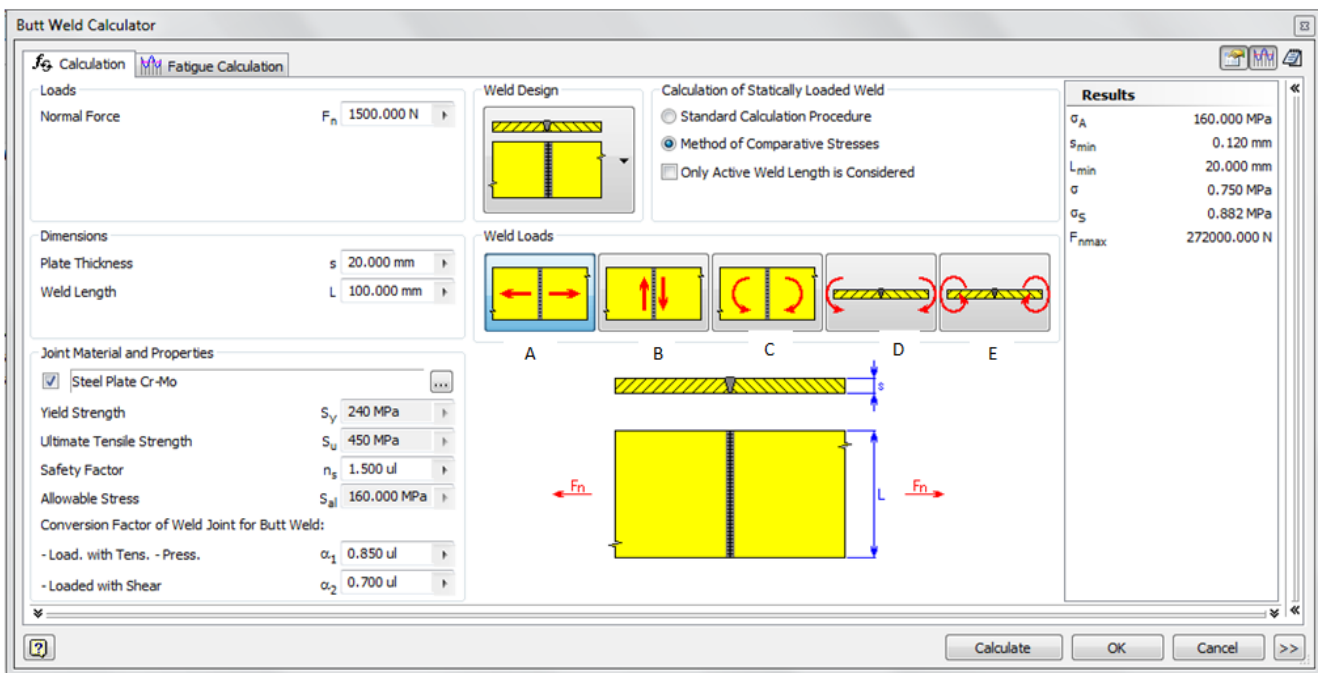

Fig. 2. Weld design using Autodesk Inventor Professional Modeling Software: $A=$ Normal force, $B=$ Shear force, $\mathrm{C}=$ Bending moment acting in the plane of welded parts, $\mathrm{D}=$ Bending moment acting in the plane perpendicular to the plane of welded parts, E = Torque. Welding calculation generated from Autodesk Inventor Professional Modelling Software

A three dimensional model designed using Autodesk Inventor Professional Modeling Software. One welding profile was assembled for study from $100 \mathrm{~mm}$ by $50 \mathrm{~mm}$ by $20 \mathrm{~mm}$ thick, shown in Fig. 3.

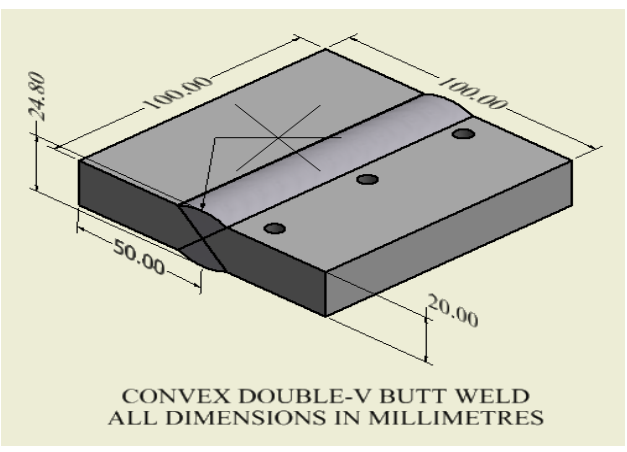

Fig. 3. A three-dimensional model 


\section{Experimental Procedure}

Before welding operation the edges of both components are double beveled so that in cross-section, the fusion faces form two opposing V's as shown in Fig. 3. Welding procedure and arrangement of the thermocouple at different distances away from the weld centreline, during experimental processes, is presented in Plate 1. TIG welding parameters considered were Material Thickness $(20 \mathrm{~mm})$, Welding Current (170/160A), Welding Pass (1p) and Tungsten Electrode diameter $(\varnothing 2 \mathrm{~mm})$. Three holes of $\varnothing 5.0 \mathrm{~mm}$ were drilled and tapped on the sample where $\mathrm{K}$ type thermocouples were planted to measure temperature fields between the base metal and welded bead which changes with time during the welding operation

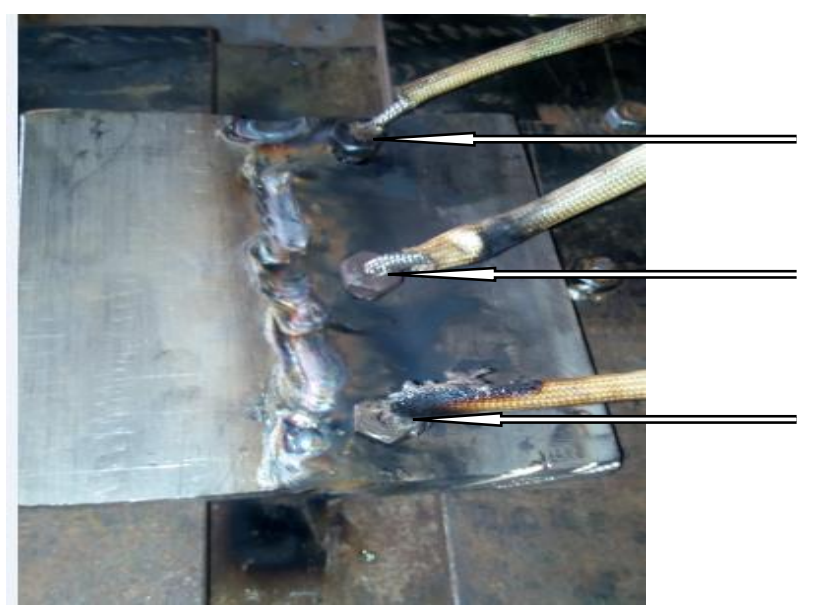

T3, at $18 \mathrm{~mm}$ depth, $12 \mathrm{~mm}$ away from
weld centre line.

$\mathrm{T} 2$, at $14 \mathrm{~mm}$ depth, $10 \mathrm{~mm}$ away from weld centre line.

$\mathrm{T} 1$, at $8 \mathrm{~mm}$ depth, $8 \mathrm{~mm}$ away from weld centre line.

Fig. 4. Specimen shown arrangement of the thermocouple at different distances away from the weld centerline

\section{Simulation Procedure and Surface Boundary Conditions/Assumptions}

Autodesk Active model in Autodesk inventor was imported into Autodesk Simulation CPD to study the temperature fields in the weld metal and base metal. The assembled specimens was simulated using Autodesk Inventor Simulation CFD 2018 Application Software which exposed temperature fields on Heat Affected Zone and weld metal Cr-Mo steel bar shown in Figs. (5-6).

On the toolbar, the following parameters were set; select material/set to solid/Cr-Mo steel.

Scenario Environment /Ambient temperature-Pressure -1atm., Temp.-27 ${ }^{\circ} \mathrm{C}$.

Material property settings - Cr-Mo steel bar.

Boundary Conditions temperature setting -Welding bead temperature set to $429.8^{\circ} \mathrm{C}$ from experimental result.

Initial Conditions-Base metal temperature set to $27^{\circ} \mathrm{C}$.

Heat transfer-Steady state, number of Iterations-0-10.

Surface-based heat transfer boundary conditions represent either a known physical state, such as temperature, or an amount of heat entering or leaving the weld metal, such as a heat flux. Temperature is the only condition that can be applied to openings and wall surfaces and others only to wall surfaces $[15,16]$.

\section{Results and discussion}

\section{Experimental results}

Temperature fields from the arrangement of the thermocouple at different distances away from the weld centreline against time are presented in Fig. 5. 
Temperature fields in Cr-Mo steel bar (100x100x20mm) during TIG welding operation on the Double Sided Half V-Groove Weld Joint.

Table 1. TIG Welding process parameters

\begin{tabular}{ll}
\hline & Machine Setting/Weld Parameters \\
\hline Material Thickness $(\mathrm{mm})$ & $20 \mathrm{~mm}$ \\
Welding Current $(\mathrm{A})$ & $170 / 160 \mathrm{~A}(\mathrm{~A})$ \\
Number of passes & 1 \\
Electrode diameter $(\varnothing \mathrm{mm})$ & $2.0 \mathrm{~mm}$ \\
\hline
\end{tabular}
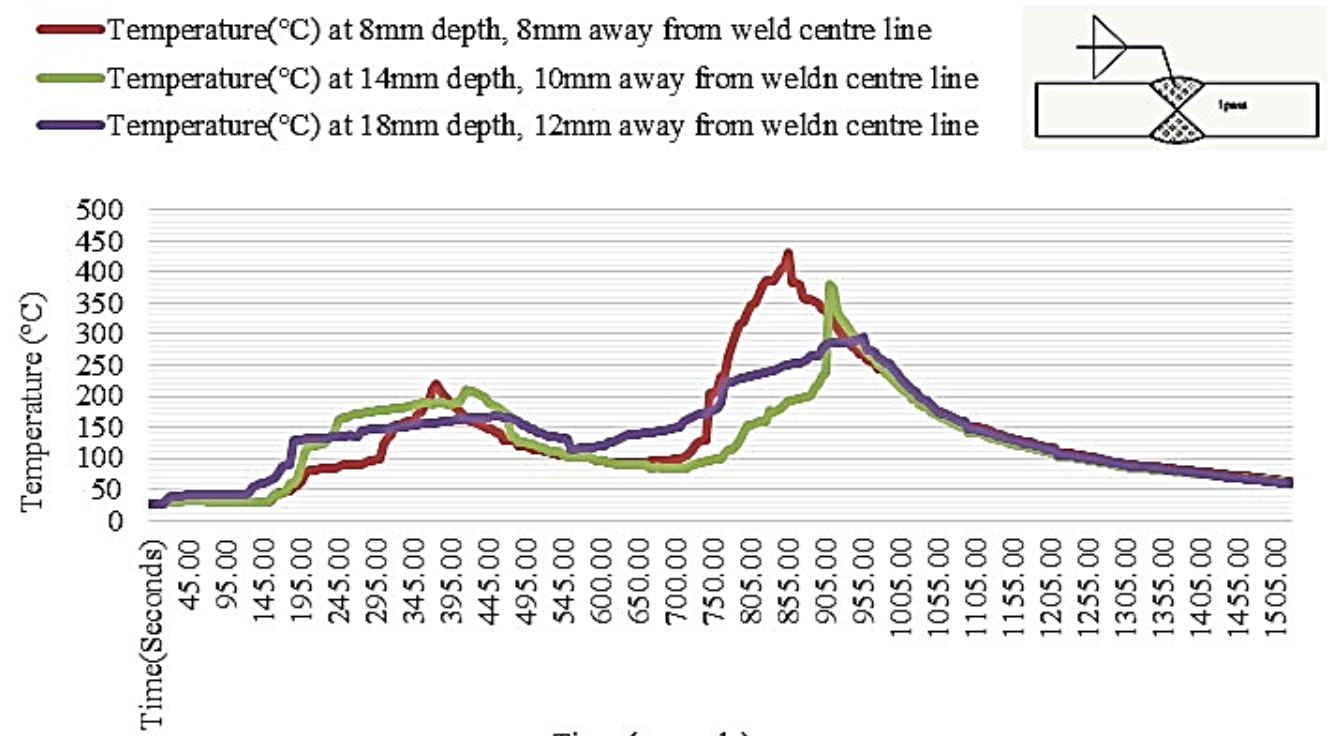

Time (seconds)

Fig. 5. Temperature fields in Cr-Mo steel bar $(100 \times 100 \times 20 \mathrm{~mm})$ during TIG welding operation

In Fig. 5 measured temperature profiles are shown during the welding experiment. The highest experimentally obtained temperature is at the peak value of the curve closest to the weld centre $(8 \mathrm{~mm})$. Also, it could be deduced that Temperature fields effect reduced away from the weld centreline. Temperature field at T1, $8 \mathrm{~mm}$ depth, $8 \mathrm{~mm}$ away from weld centre line is at its peak $429.8^{\circ} \mathrm{C}$ which is the highest and this followed by temperature field at $\mathrm{T} 2,14 \mathrm{~mm}$ depth, $10 \mathrm{~mm}$ away from weld centre line $380.6{ }^{\circ} \mathrm{C}$ and the least which is at T3, $18 \mathrm{~mm}$ depth, $12 \mathrm{~mm}$ away from weld centre line $293.9^{\circ} \mathrm{C}$.

\section{Simulation results}

The thermal simulation (temperature fields) on Cr-Mo steel using Autodesk Inventor Simulation Computational fluid dynamics (CFD) 2018 Application Software shown in Figs. (67) revealed how the temperature fields change with time. The Reddish area of the weld zone in Fig. 6 changes towards the edges of the bar. This information is use to study thermal stresses experienced within the grains which leads to failure.

A heat-affected zone (HAZ) is the part of the weldment that was not liquified during the welding operation, but whose grain structure and elemental properties were altered at elevated temperature within the weld metal. This alteration in grain structure and elemental properties leads to stresses that reduce the strength of the weld metal, and eventually causes catastrophic failures. 
Furthermore, difficult positioning welding principles and practices such as overhead and vertical welding ( $1 \mathrm{G}-6 \mathrm{G}, 1 \mathrm{~F}-4 \mathrm{~F})$ are also factors that determine the temperature fields in weld joints which leads to failure while in service, if the joint between fusion zone and weld centerline is eroded (Fig. 1).
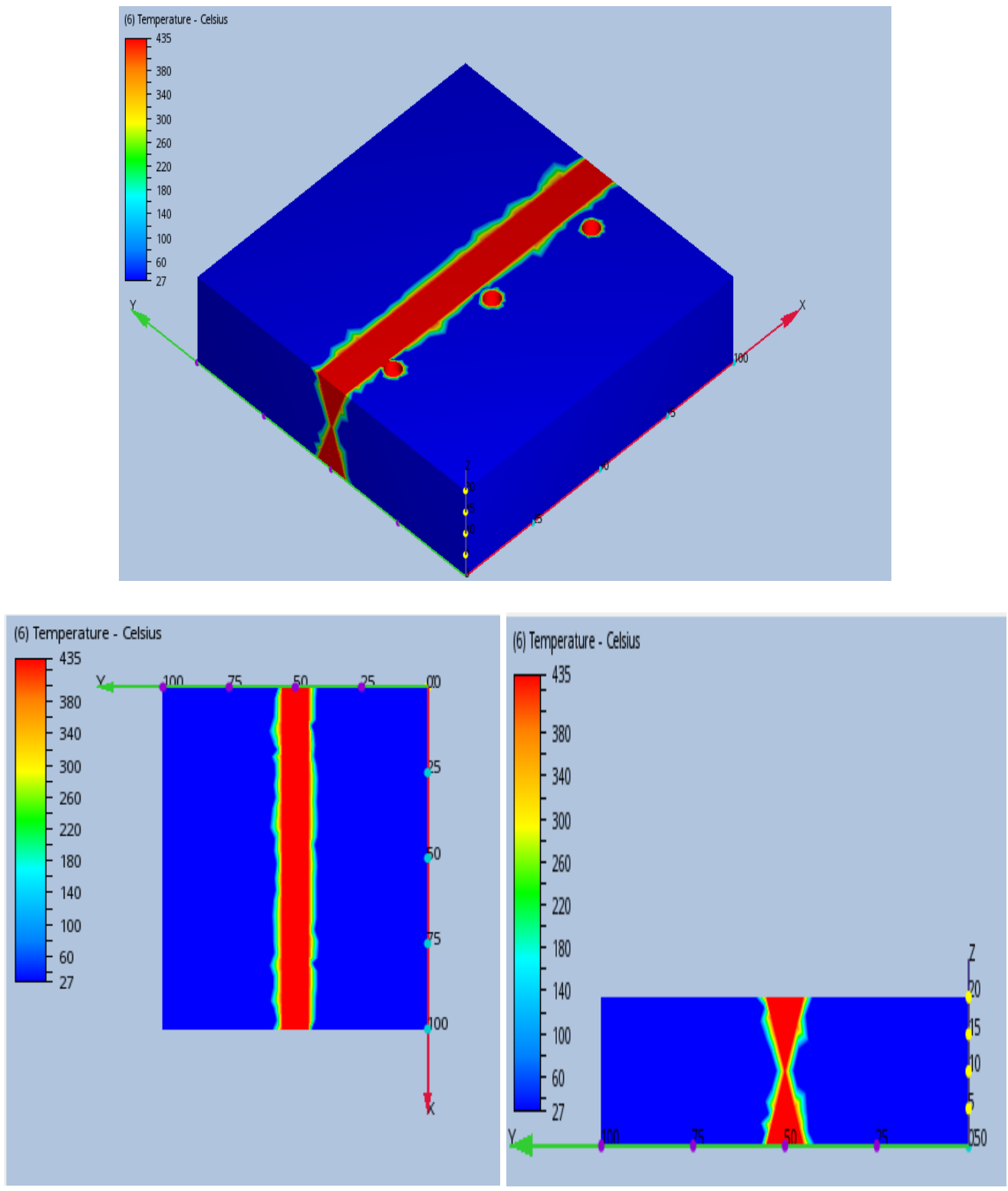

Fig. 6. Temperature distribution simulated result from the model in the welding plane 


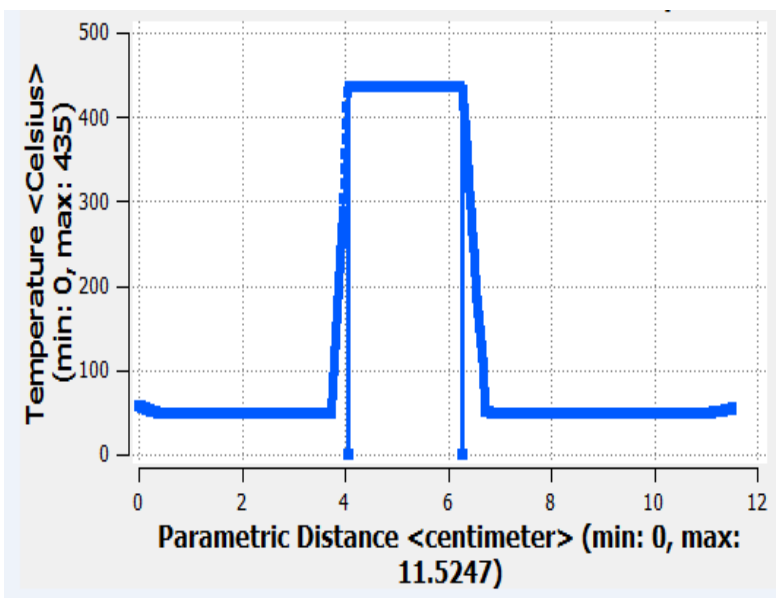

Fig. 7. Temperature distribution field in Simulated models

\section{Stress analysis report from Autodesk Inventor}

These are the analyses of the various stresses acting on the $\mathrm{X}, \mathrm{Y}$, and Z-axes model. The analyses were to use the components of the maximum and minimum values of stress derivable to determine the safety factor.

The Finite Element Analyses (FEA) results for the X, Y, and Z-axes model are shown in Tables (1-8).

Table 2. Physical properties of the weld specimen

\begin{tabular}{ll}
\hline Name & Value \\
\hline Mass & $0.216747 \mathrm{~kg}$ \\
Area & $37133.2 \mathrm{~mm}^{2}$ \\
Volume & $199747 \mathrm{~mm}^{3}$ \\
Center of Gravity & $\mathrm{X}=-288.794 \mathrm{~mm}$ \\
& $\mathrm{Y}=19.7698 \mathrm{~mm}$ \\
& $\mathrm{Z}=197.596 \mathrm{~mm}$ \\
\hline
\end{tabular}

Table 3. Material properties of the weld specimen

\begin{tabular}{lll}
\hline Name & Property & Stainless Steel (ASTM A304)) \\
\hline General & Mass Density & $8 \mathrm{~g} / \mathrm{cm}^{3}$ \\
& Yield Strength & $250 \mathrm{MPa}$ \\
& Ultimate Tensile Strength & $540 \mathrm{MPa}$ \\
Stress & Young's Modulus & $193 \mathrm{GPa}$ \\
& Poisson's Ratio & $0.3 \mathrm{ul}$ \\
& Shear Modulus & $74.2308 \mathrm{GPa}$ \\
\hline
\end{tabular}

Table 4. Operating conditions force 1 on weld specimen

\begin{tabular}{lc}
\hline Load Type & Force \\
\hline Magnitude & $1000.000 \mathrm{~N}$ \\
Vector X & $1000.000 \mathrm{~N}$ \\
Vector Y & $-0.000 \mathrm{~N}$ \\
Vector Z & $0.000 \mathrm{~N}$ \\
\hline
\end{tabular}



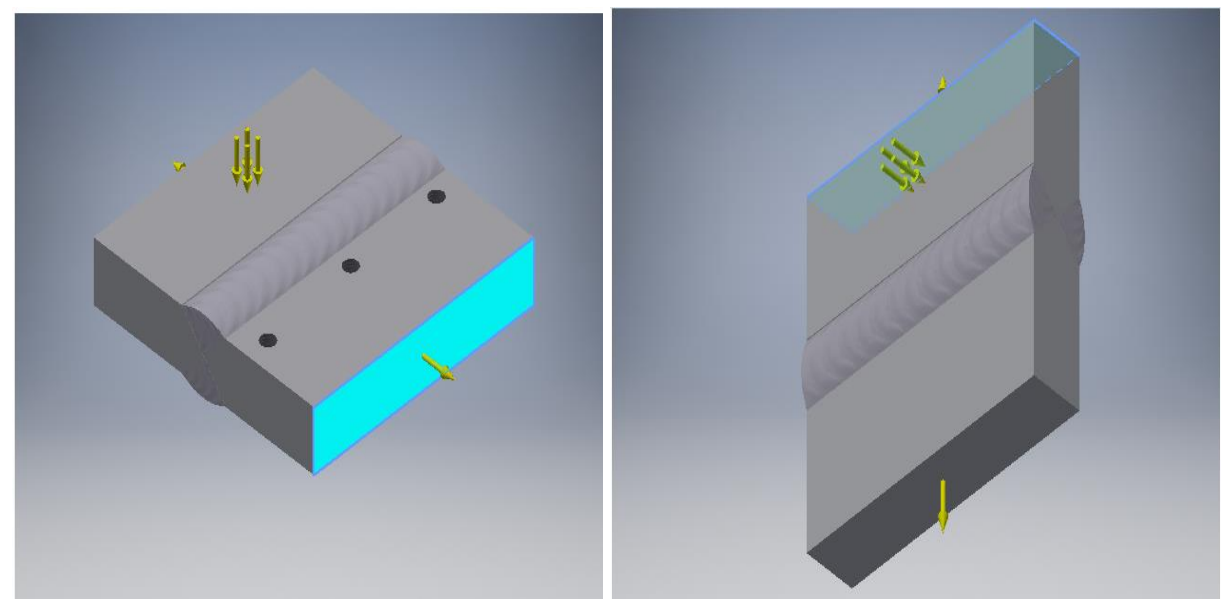

Fig. 8. Operating conditions force 1 on weld specimen Selected Face(s)

Table 5. Operating conditions force 2 on weld specimen

\begin{tabular}{lc}
\hline Load Type & Force \\
\hline Magnitude & $1000.000 \mathrm{~N}$ \\
Vector X & $-1000.000 \mathrm{~N}$ \\
Vector Y & $-0.000 \mathrm{~N}$ \\
Vector Z & $0.000 \mathrm{~N}$ \\
\hline
\end{tabular}
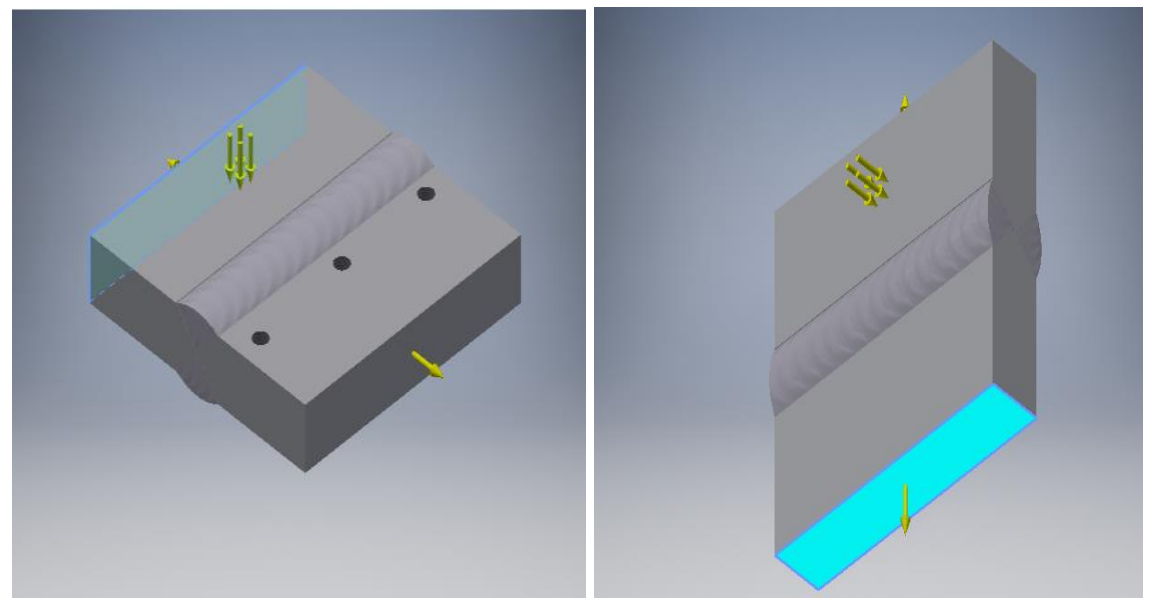

Fig. 9. Operating conditions force 2 on weld specimen Selected Face(s)

Table 6. Operating conditions pressure 1 on weld specimen

\begin{tabular}{cc}
\hline Load Type & Pressure \\
\hline Magnitude & $200.000 \mathrm{MPa}$ \\
\hline
\end{tabular}

Table 7. Operating Conditions Pressure 2 on model

\begin{tabular}{cc}
\hline Load Type & Force \\
\hline Magnitude & $200.000 \mathrm{MPa}$ \\
\hline
\end{tabular}



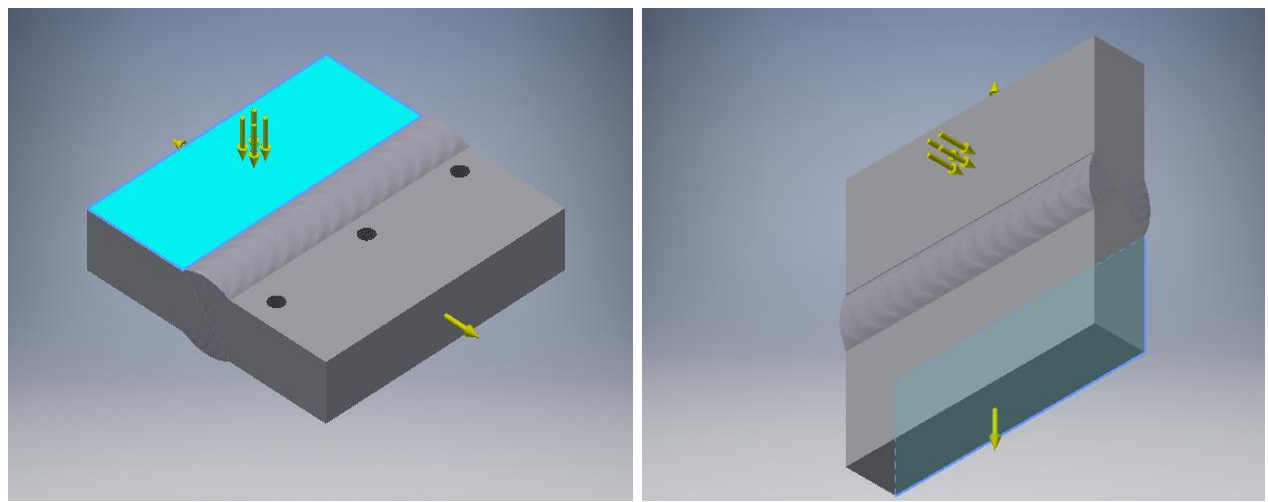

Fig. 10. Operating conditions pressure 1 on weld specimen Selected Face $(s)$
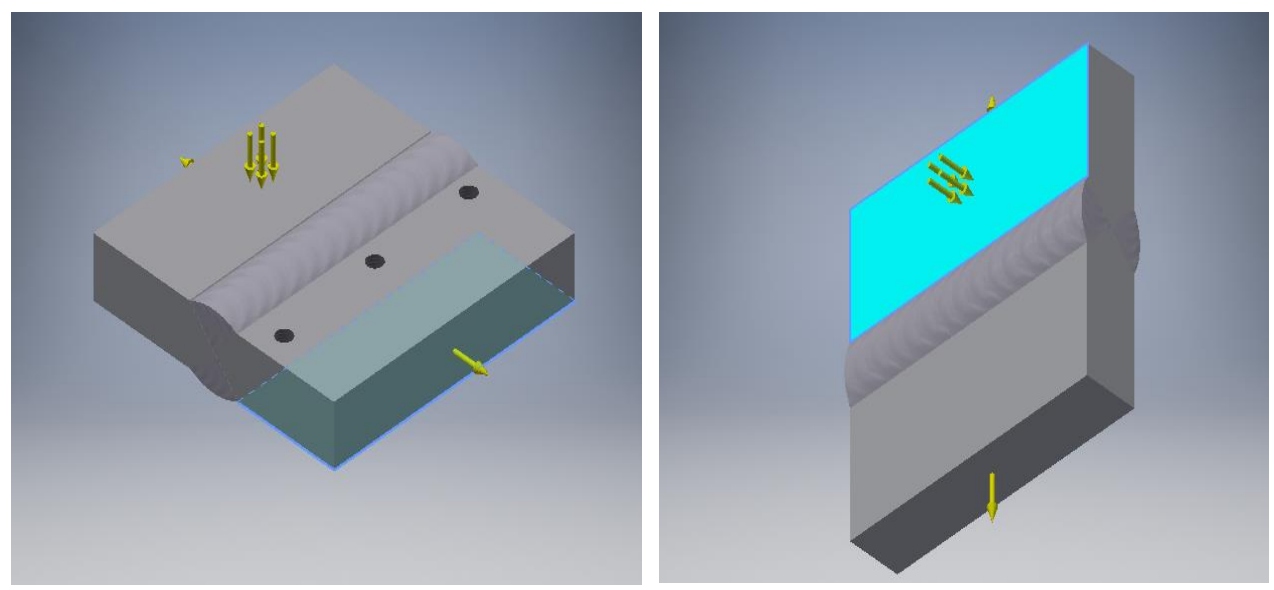

Fig. 11. Operating conditions pressure 2 on weld specimen Selected Face(s)

Table 8. Reaction force and moment on constraints model

\begin{tabular}{lcccc}
\hline Constraint Name & \multicolumn{2}{c}{ Reaction Force } & \multicolumn{2}{c}{ Reaction Moment } \\
& Magnitude & Component $(\mathbf{X , Y}, \mathbf{Z})$ & Magnitude & Component (X,Y,Z) \\
\hline \multirow{2}{*}{ Fixed Constraint:1 } & \multirow{2}{*}{$10606.5 \mathrm{~N}$} & $0 \mathrm{~N}$ & $-49394 \mathrm{~N} \mathrm{~m}$ \\
& & $0 \mathrm{~N}$ & $49394 \mathrm{~N} \mathrm{~m}$ & $0 \mathrm{~N} \mathrm{~m}$ \\
& & $-10606.5 \mathrm{~N}$ & & $0 \mathrm{~N} \mathrm{~m}$ \\
\hline
\end{tabular}

Table 9. Summary of Finite Element Analysis Result for model

\begin{tabular}{lll}
\hline Name & Minimum & Maximum \\
\hline Volume & $199747 \mathrm{~mm}^{3}$ & \\
Mass & $0.216747 \mathrm{~kg}$ & \\
Von Mises Stress & $31.0058 \mathrm{MPa}$ & $17129.1 \mathrm{MPa}$ \\
1st Principal Stress & $-3692.54 \mathrm{MPa}$ & $23603.8 \mathrm{MPa}$ \\
3rd Principal Stress & $-13330.8 \mathrm{MPa}$ & $4950.13 \mathrm{MPa}$ \\
Displacement & $0 \mathrm{~mm}$ & $5.64764 \mathrm{~mm}$ \\
Safety Factor & $0.014595 \mathrm{ul}$ & $8.06301 \mathrm{ul}$ \\
Stress XX & $-5112.61 \mathrm{MPa}$ & $8569.7 \mathrm{MPa}$ \\
Stress XY & $-2765.44 \mathrm{MPa}$ & $2327.65 \mathrm{MPa}$ \\
Stress XZ & $-1489.08 \mathrm{MPa}$ & $3508.27 \mathrm{MPa}$ \\
Stress YY & $-5739.38 \mathrm{MPa}$ & $13924.7 \mathrm{MPa}$ \\
Stress YZ & $-5633.25 \mathrm{MPa}$ & $8295.25 \mathrm{MPa}$
\end{tabular}




\begin{tabular}{lll}
\hline Name & Minimum & Maximum \\
\hline Stress ZZ & $-11416.4 \mathrm{MPa}$ & $18906.5 \mathrm{MPa}$ \\
X Displacement & $-0.0552787 \mathrm{~mm}$ & $0.0670591 \mathrm{~mm}$ \\
Y Displacement & $-0.269111 \mathrm{~mm}$ & $2.00457 \mathrm{~mm}$ \\
Z Displacement & $-5.29257 \mathrm{~mm}$ & $5.23562 \mathrm{~mm}$ \\
Equivalent Strain & $0.000148084 \mathrm{ul}$ & $0.0850456 \mathrm{ul}$ \\
1st Principal Strain & $-0.000331474 \mathrm{ul}$ & $0.101266 \mathrm{ul}$ \\
3rd Principal Strain & $-0.0562173 \mathrm{ul}$ & $-0.0000757935 \mathrm{ul}$ \\
Strain XX & $-0.0107637 \mathrm{ul}$ & $0.0115726 \mathrm{ul}$ \\
Strain XY & $-0.0186273 \mathrm{ul}$ & $0.0156785 \mathrm{ul}$ \\
Strain XZ & $-0.0100301 \mathrm{ul}$ & $0.0236309 \mathrm{ul}$ \\
Strain YY & $-0.0286534 \mathrm{ul}$ & $0.0517444 \mathrm{ul}$ \\
Strain YZ & $-0.0346116 \mathrm{ul}$ & $0.0558748 \mathrm{ul}$ \\
Strain ZZ & $-0.0449105 \mathrm{ul}$ & $0.0696261 \mathrm{ul}$ \\
Contact Pressure & $0 \mathrm{MPa}$ & $20510 \mathrm{MPa}$ \\
Contact Pressure X & $-7598.77 \mathrm{MPa}$ & $4276.95 \mathrm{MPa}$ \\
Contact Pressure Y & $-7937.96 \mathrm{MPa}$ & $4081.27 \mathrm{MPa}$ \\
Contact Pressure Z & $-17787.5 \mathrm{MPa}$ & $17067.5 \mathrm{MPa}$ \\
\hline
\end{tabular}

\section{$\boxminus$ Von Mises Stress}
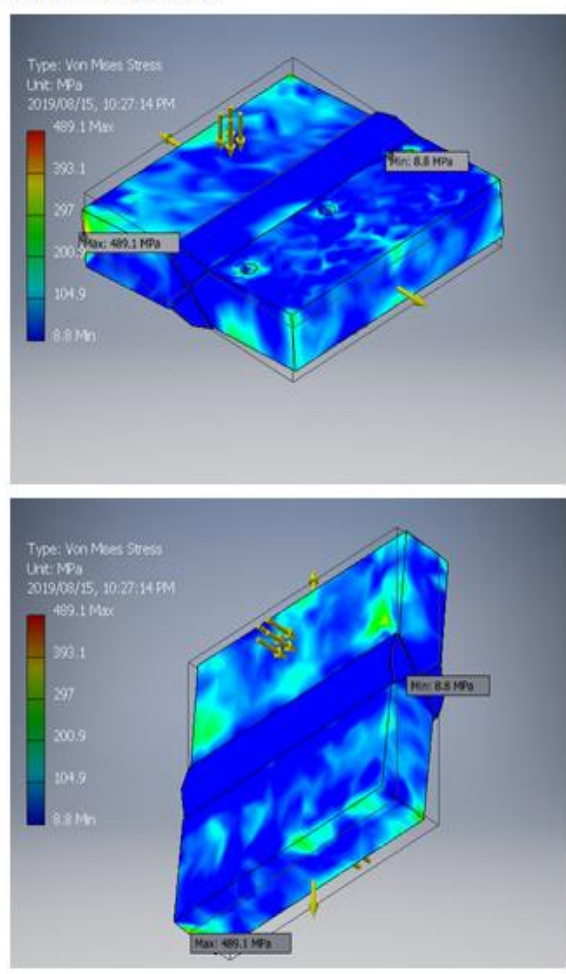

Fig. 12. Von Mises stress on weld specimen

\section{$\boxminus$ 1st Principal Stress}
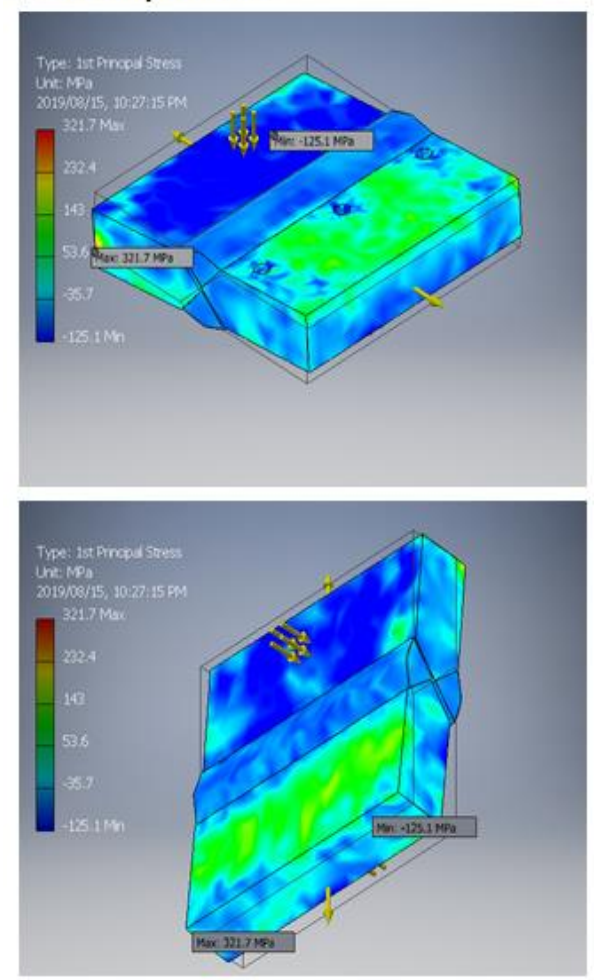

Fig.13. 1st principal stress on weld specimen 


\section{$\square$ 3rd Principal Stress}
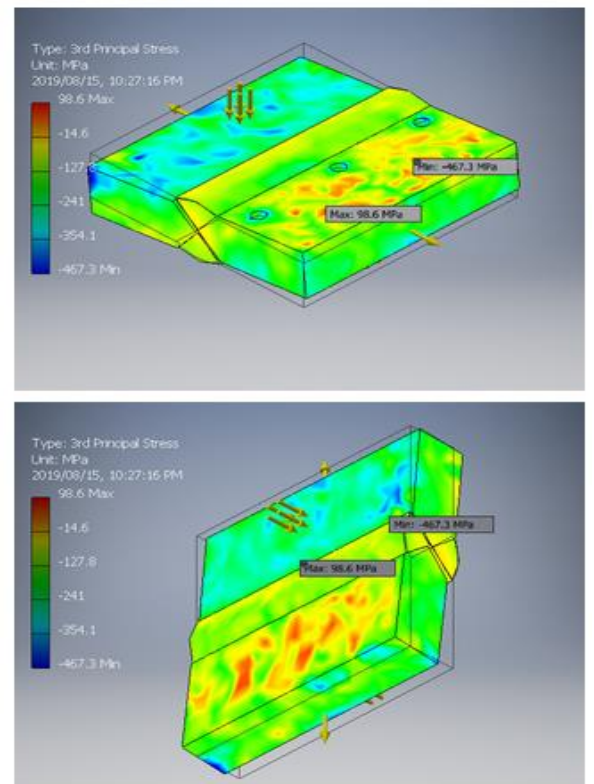

Fig. 14. 3rd Principal Stress on Weld Specimen

\section{$\boxminus$ Safety Factor}
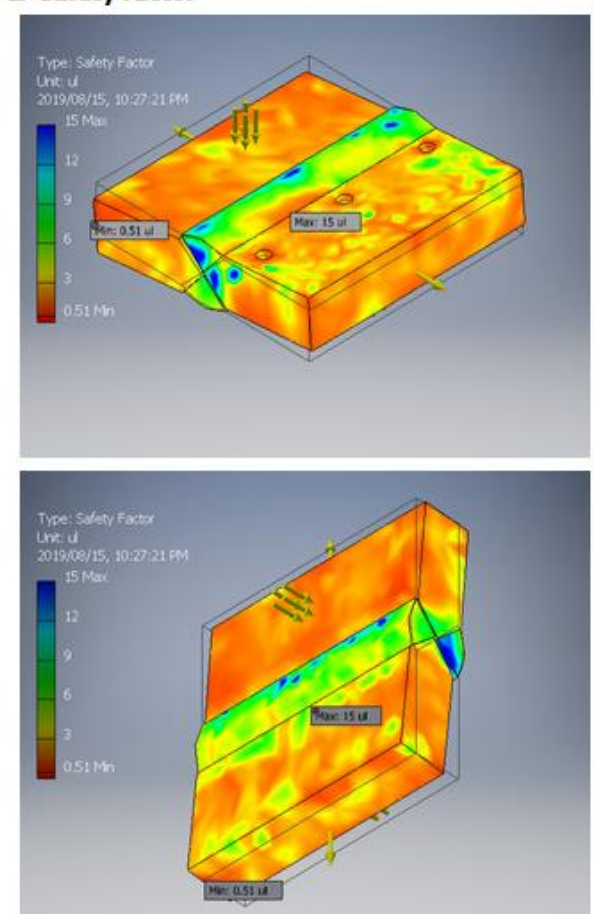

Fig. 16. Safety Factor on Weld Specimen $\boxminus$ Displacement
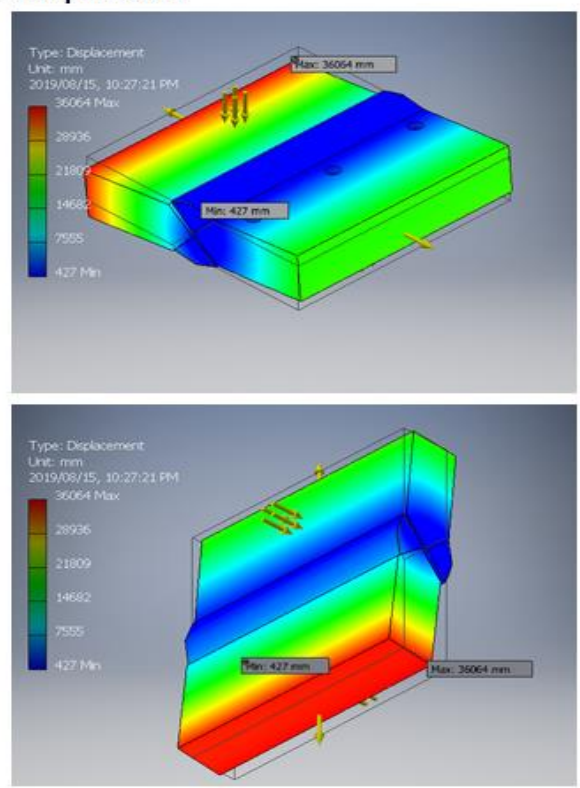

Fig. 15. Displacement on Weld Specimen
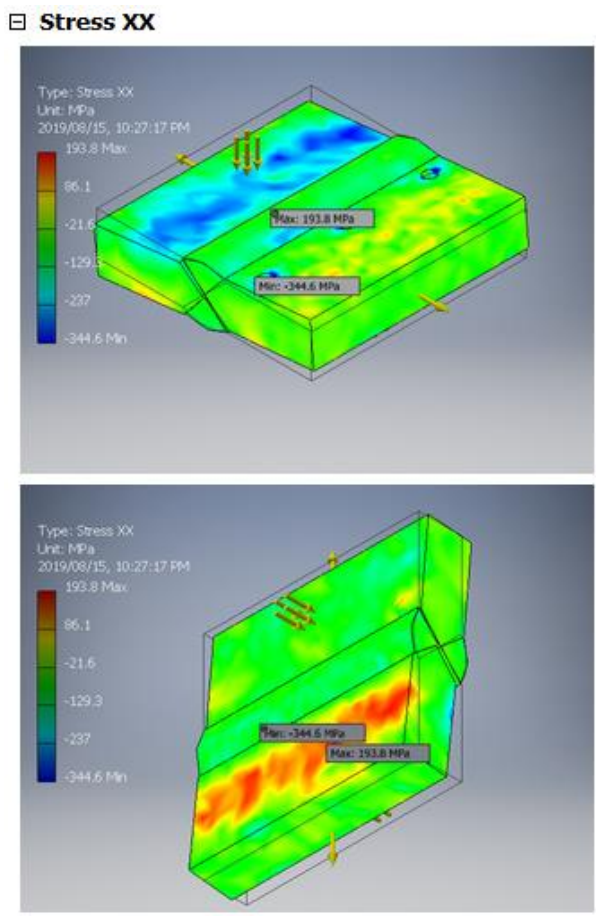

Fig. 17. Stress on XX Section 


\section{$\square$ Stress XY}
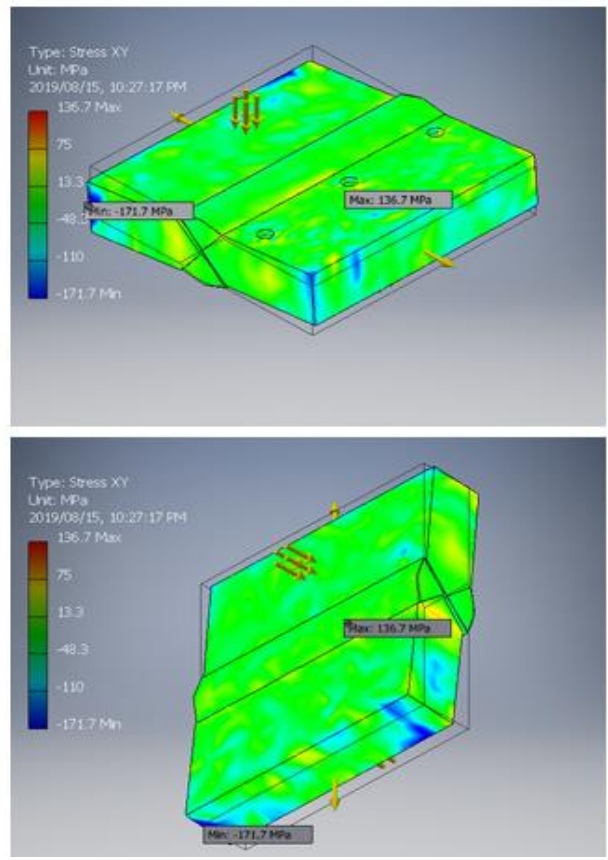

Fig. 18. Stress on XY Section
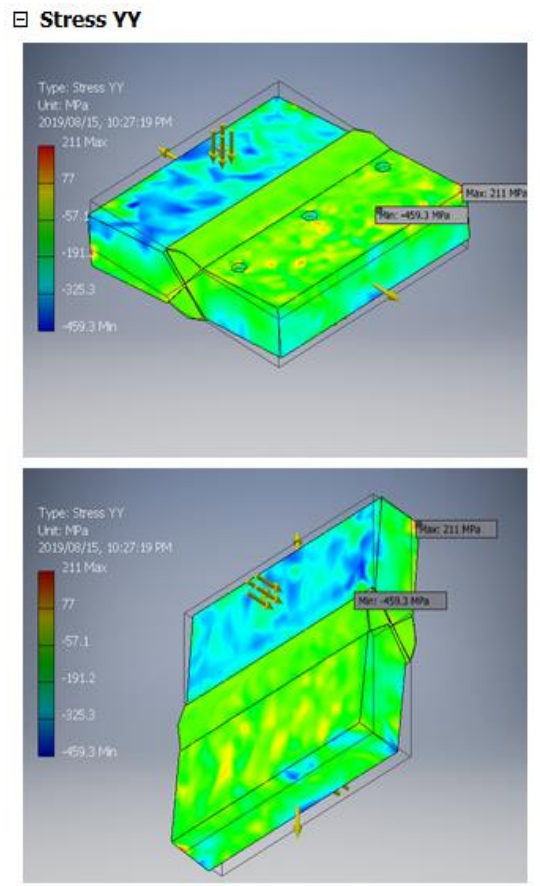

Fig. 20. Stress on YY Section

\section{$\boxminus$ Stress XZ}
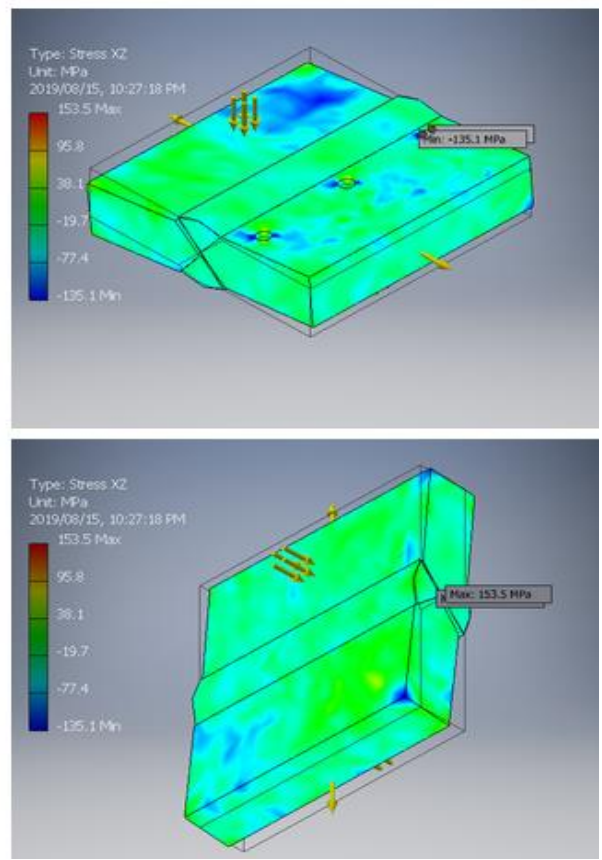

Fig. 19. Stress on $X Z$ Section

\section{$\boxminus$ Stress YZ}
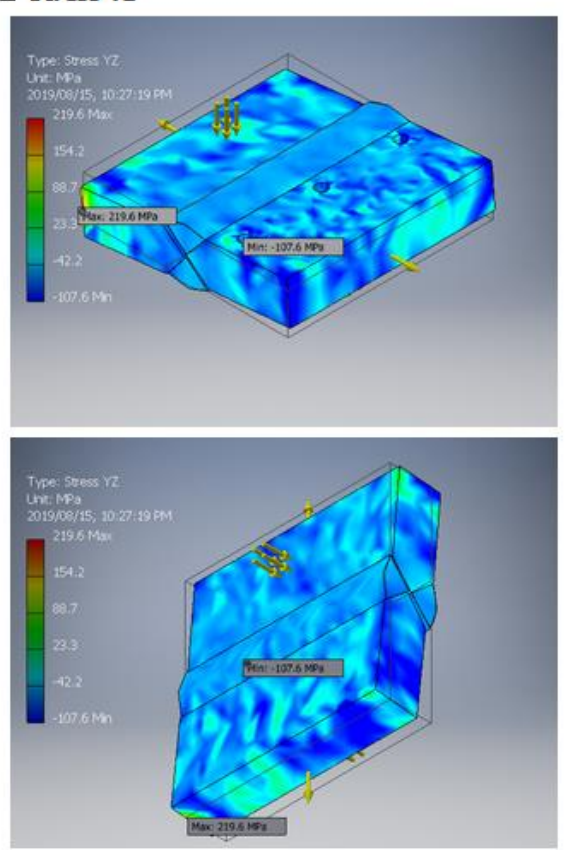

Fig. 21. Stress on YZ Section 


\section{$\boxminus$ Stress $\mathbf{Z Z}$}
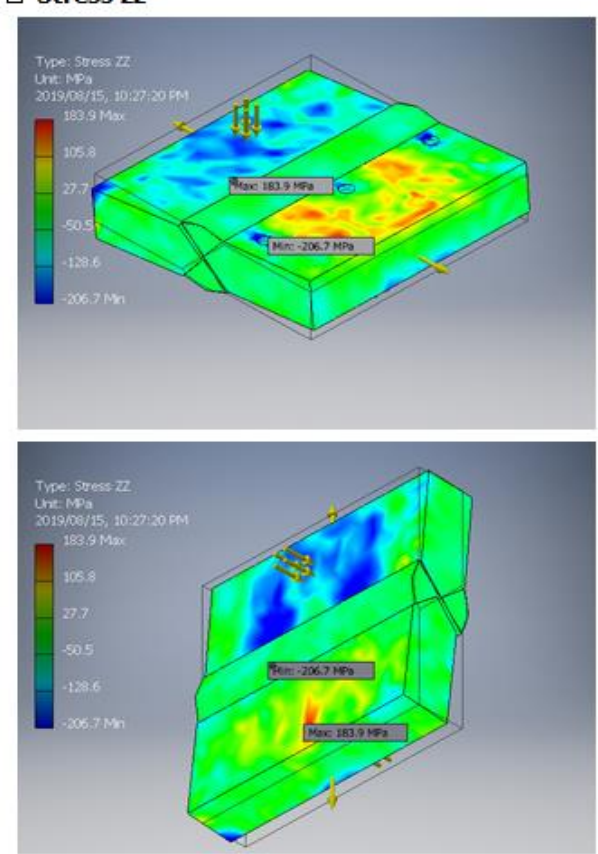

Fig. 22. Stress on ZZ Section
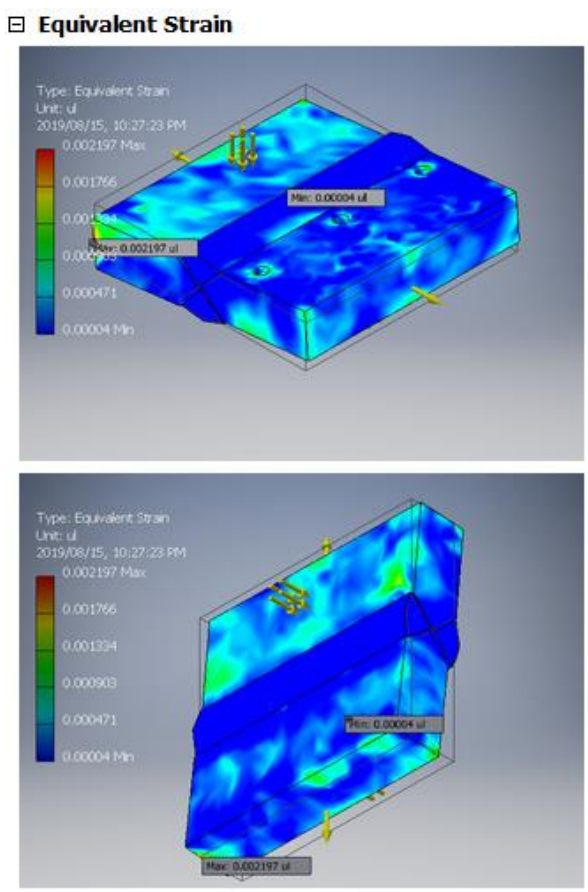

Fig. 23. Equivalent Strain

\section{$\boxminus$ Contact Pressure}
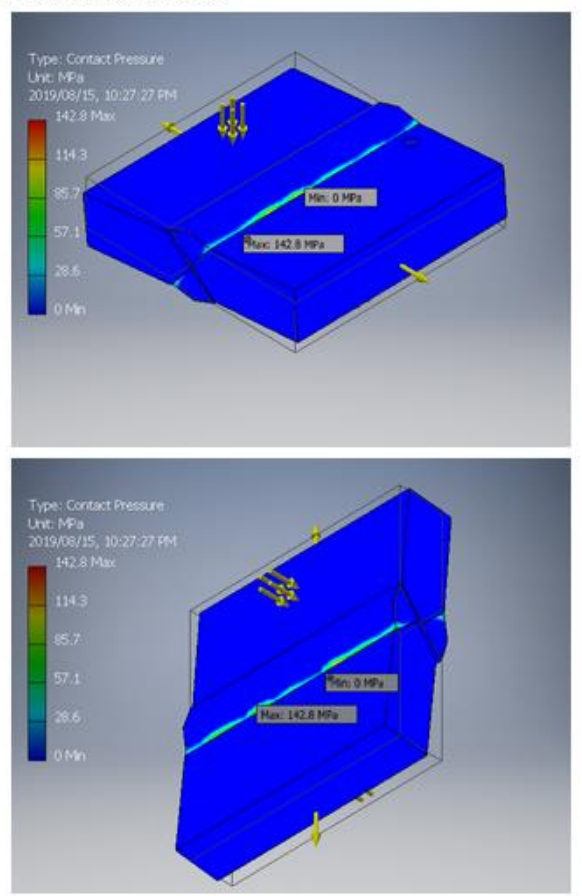

Fig. 24. Contact Pressure $\boxminus$ Contact Pressure X
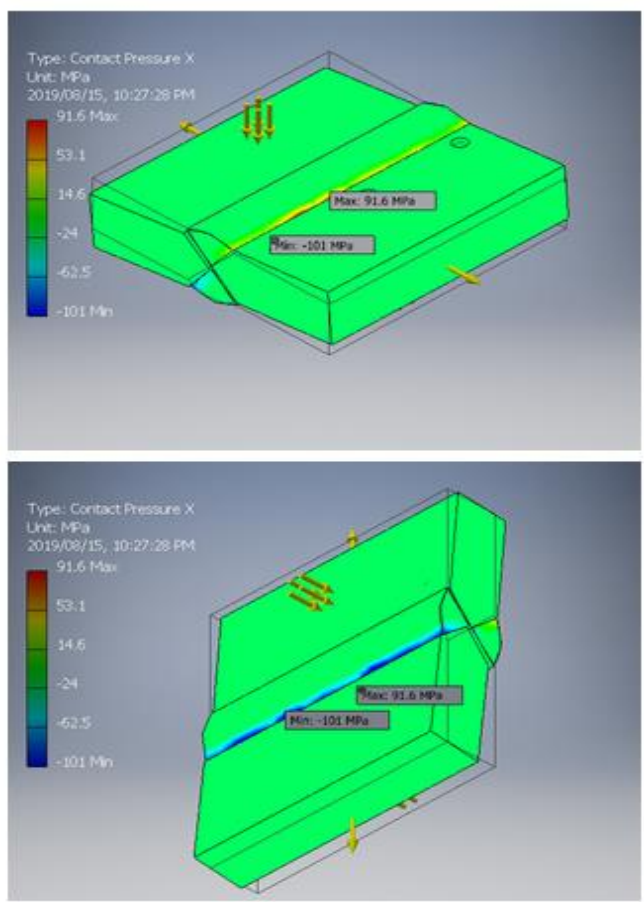

Fig. 25. Contact Pressure X 


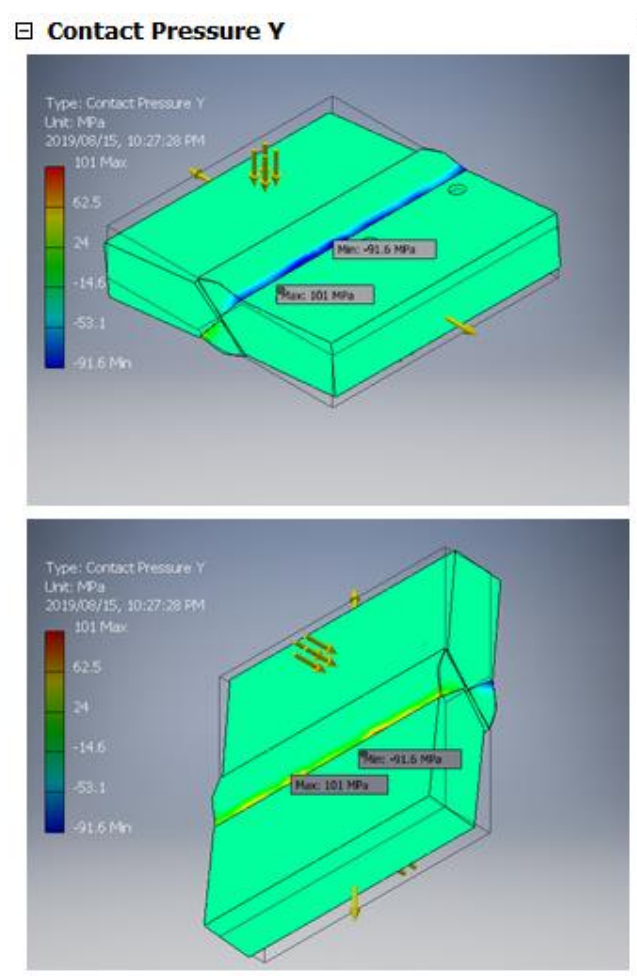

Fig. 26. Contact Pressure Y
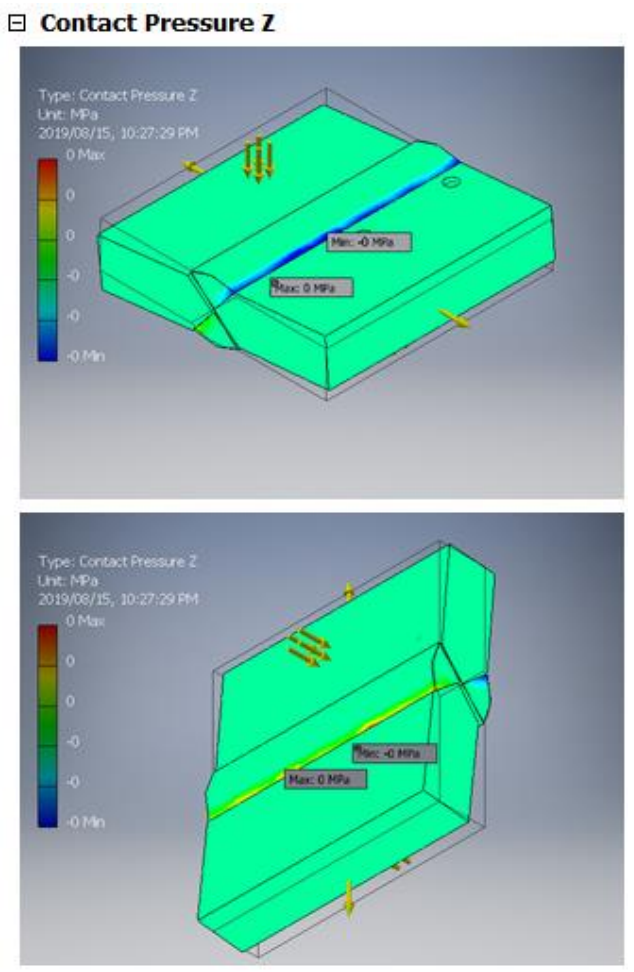

Fig. 27. Contact Pressure Z

\section{Conclusions}

It has been established that the application of Autodesk Inventor and Autodesk CFD if adopted for analysis of thermal cycle and predictions of component failure after welding operation. The following conclusions can be drawn:

Simulating welding temperature fields during and after welding operation, will be useful to predict or assess thermal stresses which may lead to failure on time.

Autodesk CFD methods reveal with reasonable accuracy the temperature fields within the weld pool and weldment and solved finite element analysis is only as good as the underlying data and assumptions.

Under complex loading from the results of uniaxial tensile tests, the Finite Element Analysis result for model revealed the likely failure while the material in use.

\section{References}

[1] Mehran G., Joseph A., Juho M., Timo B., Jari L. Finite element simulation of welding distortions in ultra-high strength steel S960 MC including comprehensive thermal and solidstate phase transformation models, Elsevier Engineering Structures 219, 2020, 110804, DOI: 10.1016/j.engstruct.2020.110804

[2] Kumar, H. CFD Simulation of Velocity and Temperature Distribution inside Refrigerator Compartment, International Journal of Engineering and Advanced Technology (IJEAT), 6, 2019, pp. 4199-4207 
[3] Xiang, J., Chen, F. F., Park, H., \& Murphy, A. B. Effects of Diffusion of Metal Vapour in an Argon TIG Welding Plasma, 13th International Conference on CFD in the Minerals and Process Industries, Melbourne, Australia, 2019

[4] Rocha, E. J. F., De Sousa Antonino, T., Guimarães, P. B., Ferreira, R. A. S., Barbosa, J. M. A., Rohatgi, J. Modeling of the temperature field generated by the deposition of weld bead on a steel butt joint by FEM techniques and thermographic images, Materials Research, 21(3), 2018, DOI: 10.1590/1980-5373-MR-2016-0796

[5] Islam, M., Buijk, A., Rais-Rohani, M., Motoyama, K. Simulation-based numerical optimization of arc welding process for reduced distortion in welded structures, Elsevier B.V.Science Direct Finite Elements in Analysis and Design, 84, 2014, pp.54-64

[6] XiaoweiPu, Chaohua Zhang., Suo Li1., Dean Deng. Simulating welding residual stress and deformation in a multi-pass butt-welded joint considering balance between computing time and prediction accuracy, International Journal of Advanced Manufacturing Technology, 93, 2017, pp.2215-2226

[7] Sun J, Deng D, Ye Y, He J, Xia L. Numerical simulation of welding residual stress in a multi-pass T-joint of thick Q390 high strength steel plate using an instantaneous heat source, Trans Chin Weld Inst., 37(7), 2016, pp.31-34 38

[8] Adewuyi, R.A., and Shuaib-Babata, Y. L. Simulation of Heat Affected Zone (HAZ)in MultiPass Welds in Low Carbon Steel, Proceedings of the 10th National Engineering Forum of School of Engineering, The Federal Polytechnic, Ado-Ekiti, 2, 2015, pp.77-83

[9] Shuaib-Babata, Y.L., Adewuyi, R.A. Effects of Thermal Treatment Processes (TTP) on the Tensile Properties of $0.165 \%$ Carbon Steel,' FUOYE Journal of Engineering and Technology, 1(1), 2016, pp.15-19

[10] Shuaib-Babata, Y. L., Adewuyi, R.A., Aweda, J. O. Effects of Thermal Treatment Processes (TTP) on some of the Mechanical Properties of welded 0.165\% Carbon Steel, Journal of Production Engineering, (JPE), 20(1), 2017, pp.101-111

[11] Adewuyi, R.A., Elegbeleye, K.E. Impact of Post-Weld Heat Treatment (PWHT) on the Hardness and Microstructure of Low Carbon Steel. International Journal of Innovative Science, Engineering \& Technology, 3(11), 2016, pp.16-26

[12] Chen, B.Q., Soares, C.G. Effect of welding sequence on temperature distribution, distortions, and residual stress on stiffened plates, Int J AdvManufTechnol, 86, 2016, pp.3145-3156

[13] Nezamdost, M.R., Esfahani, M.R.N., Hashemi, S.H., Mirbozorgi, S.A. Investigation of temperature and residual stresses field of submerged arc welding by finite element method and experiments, ' Int J AdvManuf Technol., 87, 2016, pp.615-624

[14] Rajput, E. Heat-and-mass-transfer. (5th, Ed.) New Delhi: S. Chand \& Company Ltd., 2012 Experimental Analysis on TIG welding process parameters of dissimilar metals SS304SS202 using the Taguchi Method. International Journal of Engineering and Manufacturing Science, 7 , 2017, pp. 249-258

[15] Hongbin, D., Xiuqiang, S., \& Haoran, W. The influence of TIG-Arc physical characteristics on the penetration and weld width under different Ar and He supply conditions, Results in Physics, 9, 2018, pp.1120-1126

[16] Xiaowei, P., Zhang, C., SuoLi, \& Deng, D. Simulating welding residual stress and deformation in a multi-pass butt-welded joint considering balance between computing time and prediction accuracy, The International Journal of Advanced Manufacturing Technology, 2017, DOI: 10.1007/s00170-017-0691-5 
[17] Park, H. K.,Trautmann, M., Tanaka, K., Tanaka, M., Murphy,A. B. Mixing of multiple metal vapours into an arc plasma in gas tungsten arc welding of stainless steel, Journal of Physics D: Applied Physics, 50(43), 2017, 43LT03

[18] Lundbäck, A. Modelling and Simulation of Welding and Metal Deposition, Luleå University of Technology Department of Applied Physics and Mechanical Engineering Division of Computer Aided Design 2010

Received: December 04, 2020

Accepted: January 21, 2021 